\title{
In situ crosslinked electrospun gelatin nanofibers for skin regeneration
}

\section{DOI:}

10.1016/j.eurpolymj.2017.08.015

\section{Document Version}

Accepted author manuscript

Link to publication record in Manchester Research Explorer

\section{Citation for published version (APA):}

Dias, J. R., Baptista-Silva, S., de Oliveira, C. M. T., Sousa, A., Oliveira, A. L., Da Silva Bartolo, P. J., \& Granja, P. L. (2017). In situ crosslinked electrospun gelatin nanofibers for skin regeneration. European Polymer Journal, 95, 161-173. https://doi.org/10.1016/j.eurpolymj.2017.08.015

\section{Published in:}

European Polymer Journal

\section{Citing this paper}

Please note that where the full-text provided on Manchester Research Explorer is the Author Accepted Manuscript or Proof version this may differ from the final Published version. If citing, it is advised that you check and use the publisher's definitive version.

\section{General rights}

Copyright and moral rights for the publications made accessible in the Research Explorer are retained by the authors and/or other copyright owners and it is a condition of accessing publications that users recognise and abide by the legal requirements associated with these rights.

\section{Takedown policy}

If you believe that this document breaches copyright please refer to the University of Manchester's Takedown Procedures [http://man.ac.uk/04Y6Bo] or contact uml.scholarlycommunications@manchester.ac.uk providing relevant details, so we can investigate your claim.

\section{OPEN ACCESS}




\title{
Manuscript Details
}

\section{Manuscript number}

Title

Article type
EUROPOL_2017_546

In situ crosslinked electrospun gelatin nanofibers for skin regeneration

Research paper

\begin{abstract}
Due to its intrinsic similarity to the extracellular matrix, gelatin electrospun nanofibrous meshes are promising scaffold structures for wound dressings and tissue engineering applications. However, gelatin is water soluble and presents poor mechanical properties, which generally constitute relevant limitations to its applicability. In this work, gelatin was in situ crosslinked with 1,4-butanediol diglycidyl ether (BDDGE) at different concentrations (2, 4 and 6 wt- $\%)$ and incubation time-points $(24,48$ and $72 \mathrm{~h})$ at $37^{\circ} \mathrm{C}$. The physico-chemical and biological properties of BDDGEcrosslinked electrospun gelatin meshes were investigated. Results show that by changing the BDDGE concentration it is possible to produce nanofibers crosslinked in situ with well-defined morphology and modulate fiber size and mechanical properties. Crosslinked gelatin meshes show no toxicity towards fibroblasts, stimulating their adhesion, proliferation and synthesis of new extracellular matrix, thereby indicating the potential of this strategy for skin tissue engineering.
\end{abstract}

\section{Keywords}

Manuscript category

Corresponding Author

Order of Authors

Suggested reviewers
Keywords: In situ crosslinking, Electrospun fibers, gelatin, BDDGE, wound dressing.

Regular Paper

Juliana Dias

Juliana Dias, Sara Baptista-Silva, Carla Oliveira, Aureliana Sousa, Ana Oliveira, Paulo Bartolo, Pedro Granja

Lorenzo Moroni, Seeram Ramakrishna,FREng, Raul Machado, Julio San

Roman, Helena Gil

\section{Submission Files Included in this PDF}

\section{File Name [File Type]}

Cover Letter.pdf [Cover Letter]

Graphical Table of Contents.docx [Graphical Abstract]

In situ crosslinked electrospun gelatin nanofibers for skin regeneration.docx [Manuscript File]

Highlights.docx [Highlights]

To view all the submission files, including those not included in the PDF, click on the manuscript title on your EVISE Homepage, then click 'Download zip file'. 


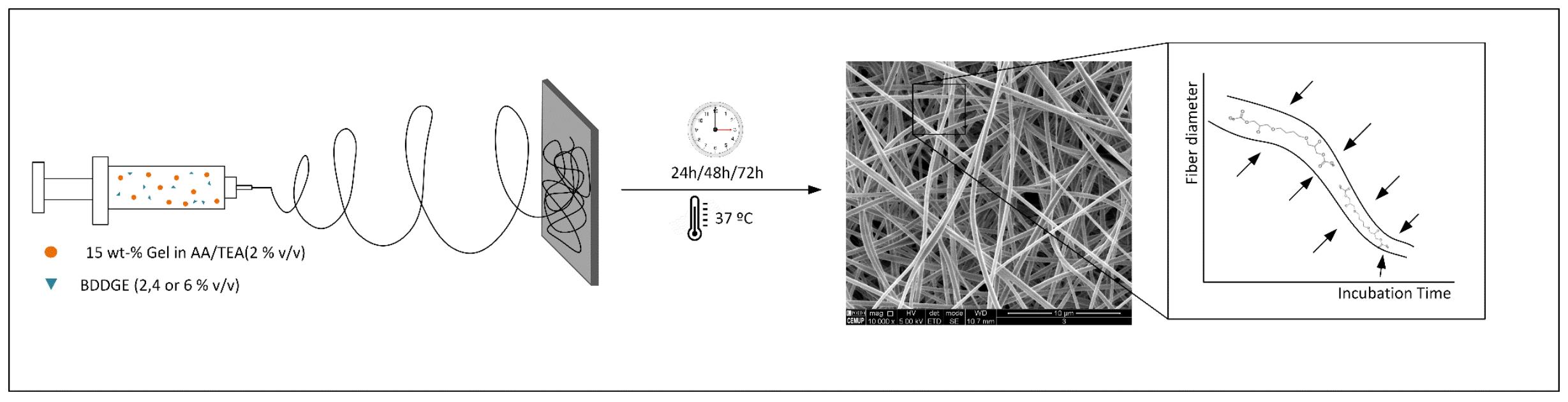

Graphical Table of Contents

In situ crosslinking of gelatin electrospun fibers with BDDGE is describe for the first time. The results demonstrate a huge potential to keep the fibers morphology after crosslinking. Changing both the crosslinker amount and the incubation time it is possible to control the crosslinking reaction and, consequently, the mesh properties (morphological, mechanical and biological properties). 


\section{In situ crosslinked electrospun gelatin nanofibers for skin regeneration}

J.R. Dias ${ }^{1,2,3,4^{*}}$, S. Baptista-Silva ${ }^{5}$, C.M.T. de Oliveira ${ }^{1,3,6}$, A. Sousa ${ }^{1,3}$, A.L. Oliveira ${ }^{5}$, P. J. Bártolo ${ }^{8}$, P.L. Granja ${ }^{1,3,4,7}$

${ }^{1}$ Instituto de Investigação e Inovação em Saúde (i3S), Universidade do Porto, Porto, Portugal

${ }^{2}$ Centre for Rapid and Sustainable Product Development (CDRsp), Polytechnic Institute of Leiria, Leiria, Portugal

${ }^{3}$ Instituto de Engenharia Biomédica (INEB), Universidade do Porto, Porto, Portugal

${ }^{4}$ Instituto de Ciências Biomédicas Abel Salazar (ICBAS), Universidade do Porto, Porto, Portugal

${ }^{5}$ Center for Biotechnology and Fine Chemistry (CBQF), School of Biotechnology, Portuguese Catholic University, Porto, Portugal

${ }^{6}$ Escola Superior de Tecnologia da Saúde do Porto (ESTSP/IPP), Porto, Portugal

${ }^{7}$ Faculdade de Engenharia da Universidade do Porto (FEUP), Porto, Portugal

${ }^{8}$ School of Mechanical, Aerospace and Civil Engineering \& Manchester Institute of Biotechnology, University of Manchester, UK

${ }^{*}$ Corresponding author at Biomaterials for Multistage Drug \& Cell Delivery Group, Instituto de Investigação e Inovação em Saúde, Universidade do Porto, Rua Alfredo Allen, 208

4200-135 Porto, Portugal . Phone number +351 220408 800, Fax +351 226094 567, e-mail address:juliana.dias@ineb.up.pt 


\section{Abstract}

Due to its intrinsic similarity to the extracellular matrix, gelatin electrospun nanofibrous meshes are promising scaffold structures for wound dressings and tissue engineering applications. However, gelatin is water soluble and presents poor mechanical properties, which generally constitute relevant limitations to its applicability. In this work, gelatin was in situ crosslinked with 1,4-butanediol diglycidyl ether (BDDGE) at different concentrations (2, 4 and 6 wt-\%) and incubation time-points $(24,48$ and $72 \mathrm{~h})$ at $37^{\circ} \mathrm{C}$. The physico-chemical and biological properties of BDDGE-crosslinked electrospun gelatin meshes were investigated. Results show that by changing the BDDGE concentration it is possible to produce nanofibers crosslinked in situ with well-defined morphology and modulate fiber size and mechanical properties. Crosslinked gelatin meshes show no toxicity towards fibroblasts, stimulating their adhesion, proliferation and synthesis of new extracellular matrix, thereby indicating the potential of this strategy for skin tissue engineering.

Keywords: In situ crosslinking, Electrospun fibers, gelatin, BDDGE, wound dressing.

\section{Introduction}

Skin is the largest vital organ in the body, protecting it against the external environment [1-5]. Although skin has a self-regeneration ability, this capacity is strongly reduced in the case of full-thickness lesions, making necessary the use of grafts or dressings [1]. The usual procedure when skin damage occurs consists in the application of a wound dressing due their efficiency, low cost and availability [6, 7]. Wound dressings made from electrospun nanofibers present advantageous properties compared to conventional dressings such as the potential to promote the hemostasis phase, wound exudate absorption, semi-permeability, easy conformability to the wound, functional ability and no scar induction [8]. 
Gelatin, derived from collagen, is a natural mimic of the extracellular matrix (ECM) of human tissues and organs and is widely used in the tissue engineering field due to of its excellent biological origin, biocompatibility, biodegradability non-immunogenicity, cellinteractivity and commercial availability $[9,10]$. However, gelatin is a water-soluble protein derived from partial hydrolysis of collagen and crosslinking is usually needed to improve its mechanical properties and stability, making gelatin scaffolds insoluble in biological environments [10]. Several gelatin crosslinking methods are available, such as enzymatic using transglutaminase [11, 12], or chemical using fructose [13], dextran dialdehyde [14], diepoxy [15], formaldehyde [16], glutaraldehyde [13, 16, 17], genipin [15, 18, 19], diisocyanates [20], or carbodiimides [21]. The widely used aldehyde-based crosslinking strategy has provided a powerful tool to tailor the physical properties of gelatin films [22-24] although the assumed toxicity of such chemicals makes their use uncertain [22]. Epoxy compounds are preferred as a stabilizing agent of collagen-based materials for biomedical applications due to their lower toxicity compared to commonly used dialdehydes [25-27].

The search for alternative crosslinkers presenting low toxicity and good stability is the main objective of this research work. Amongst water-soluble polyepoxides, 1,4butanediol diglycidyl ether (BDDGE) is commercially available as a crosslinking agent in dermal filler formulations [26]. Although un-reacted BDDGE should be considered from slightly to moderately toxic [27], residual BDDGE might undergo hydrolysis yielding a diol-ether (3,3'(butane-1,4-diylbis(oxy)) bis propane-1,2-diol), which has been proven non-toxic, thus limiting safety risks [26]. This study evaluates the ability of BDDGE to crosslink electrospun gelatin nanofibers and provides the first insights on the physicochemical and in vitro biological performance of produced scaffolds in the context of skin tissue engineering applications.

\section{Materials and Methods}

\subsection{Materials}


Gelatin powder of pig skin (type A, 300 bloom, 60 mesh) was kindly supplied by Italgelatine (Italy). Acetic acid (AA) glacial was purchased from PanReac AppliChem, triethylamine (TEA) from Sigma Aldrich, and 1,4-butanediol diglycidyl ether (BDDGE) from Alpha Aesar. All materials used were of reagent grade and used without any further purification.

\subsection{Electrospinning of crosslinked gelatin nanofiber meshes}

A gelatin/AA/TEA solution was prepared by dissolving gelatin (15 wt-\%) in AA and then adding 2 wt- $\%$ of TEA to the solution and stirring at $37^{\circ} \mathrm{C}$ overnight. TEA was added to increase the solution's conductivity. Crosslinking of electrospun gelatin fibers was carried out through the incorporation of BDDGE on the gelatin solution immediately before fiber electrospinning to avoid the loss of configuration that is induced through a crosslinking bath after fiber production. The effect of different BDDGE concentrations (2, 4 and 6 wt$\%)$ at varied time-points (24, 48 and $72 \mathrm{~h})$ was tested.

Gelatin nanofibrous meshes were processed using a home-made electrospinning apparatus. Non-woven gelatin electrospun meshes were obtained at room temperature (RT) and relative humidity of $40-50 \%$ with a constant flow rate of $0.4 \mathrm{~mL} / \mathrm{h}$ (SP11Elite, Harvard Apparatus) and $11 \mathrm{kV}$ of voltage. A grounded copper plate was used as collector and it was positioned $12 \mathrm{~cm}$ away from the needle tip.

\subsection{Physico-chemical characterization}

\subsubsection{Apparent density and porosity}

The apparent density and porosity of gelatin electrospun meshes were calculated using equations (1) and (2) [28], respectively, and the mesh thickness was measured using a micrometer.

$$
\begin{aligned}
& \text { Apparent density }\left(\mathrm{g} \cdot \mathrm{cm}^{-3}\right)=\frac{\text { mesh mass }(\mathrm{g})}{\text { mesh thickness }(\mathrm{cm}) \cdot \text { mesh area }\left(\mathrm{cm}^{2}\right)} \\
& \text { Mesh porosity }=\left(1-\frac{\text { Mesh apparent density }\left(\mathrm{g} \cdot \mathrm{cm}^{-3}\right)}{\text { Bulk density of gelatin }\left(\mathrm{g} \cdot \mathrm{cm}^{-3}\right)}\right) \cdot 100 \%
\end{aligned}
$$




\subsubsection{Morphology and fiber diameter}

The morphology of each electrospun fibrous mesh was examined by scanning electron microscopy (SEM) using a Quanta 400 FEG ESEM/EDAX Genesis X4M (FEI Company, USA). Prior to examination samples were coated with a gold/palladium ( $\mathrm{Au} / \mathrm{Pd}$ ) thin film, by sputtering, using the SPI Module Sputter Coater equipment. SEM images were also used to evaluate the fiber diameter distribution using Image $\mathrm{J}$ software. To each condition three individual samples were analyzed and fifty measurements per image were carried out.

\subsubsection{Mesh Structure}

Fourier transform infrared (FTIR) spectroscopy with attenuated total reflectance (ATR) was used to evaluate the chemical composition of the materials and to detect possible structural changes. FTIR analyses were carried out using an Alpha-P Brucker FTIR-ATR spectrometer, in the range of $4000-500 \mathrm{~cm}^{-1}$, at a $4 \mathrm{~cm}^{-1}$ resolution with 64 scans.

\subsubsection{Crosslinking extent}

The ninhydrin (NHN) assay was used to quantify the number of amino groups involved in the crosslinking reaction through UV-vis spectrometry. Crosslinked gelatin electrospun meshes with different crosslinker percentages and dried after different periods of time were tested. A precise amount of sample $(10.5 \pm 0.5 \mathrm{mg})$ was heated with ninhydrin solution $(200 \mathrm{mg} / 100 \mathrm{~mL})$ for $10 \mathrm{~min}$ in a water bath at $90^{\circ} \mathrm{C}$. Afterwards, $5 \mathrm{~mL}$ of ethanol was added to $100 \mu \mathrm{L}$ of each sample and the absorbance recorded on a spectrophotometer (lambda 35 from Perkin Elmer, USA) at a wavelength of $570 \mathrm{~nm}$ with glycine as standard. Linear regression was performed with a correlation of 0.9976 . The extent of crosslinking was defined according to eq. 3 :

$$
\text { Crosslinking degree }(\%)=\left(1-\frac{\mathrm{NH}_{\mathrm{t}}}{\mathrm{NH}_{0}}\right) \cdot 100
$$


where, $\mathrm{NH}_{0}$ is the amount of free amino groups in the gelatin before crosslinking and $\mathrm{NH}_{\mathrm{t}}$ is the amount of free amino groups after crosslinking [29].

\subsubsection{Dissolvability and water uptake}

To assess the dissolvability, samples were dried for $24 \mathrm{~h}$ before weight determination, followed by incubation in distilled water and sodium azide $(0.02 \%)$ as bacteriostatic agent. After $24 \mathrm{~h}$ of incubation samples were removed from the distilled water solution and weighted again to evaluate the swelling degree (eq. 4). Then, the samples were dried for an additional $24 \mathrm{~h}$ period at $37^{\circ} \mathrm{C}$ and weighted to evaluate their dissolvability (eq. 5).

$$
\text { Degree of sweeling }(\%)=\frac{\mathrm{W}_{\mathrm{w}}-\mathrm{W}_{\mathrm{d}}}{\mathrm{w}_{\mathrm{d}}} \cdot 100 \text {, }
$$

where $W_{w}$ is the wet weight and $W_{d}$ is the dry weight.

$$
\text { Dissolvability }(\%)=\frac{\mathrm{W}_{0}-\mathrm{W}_{\mathrm{d}}}{\mathrm{W}_{0}} \cdot 100,
$$

where $W_{0}$ is the initial weight and $W_{d}$ is the dry weight.

\subsubsection{Water vapor permeability}

To evaluate the water permeation rate of electrospun meshes, glass bottles with the same size and type were filled with PBS solution and the electrospun meshes were fixed on their openings. The area available for vapor permeation was $2.39 \mathrm{~cm}^{2}$. Evaporation of water through the mesh was monitored by the measurement of weight loss according to standard test methods for water vapor transmission [30]. Briefly, each set was weighted and kept at $32^{\circ} \mathrm{C}$ during $24 \mathrm{~h}$, after which the weight of each set was recorded again to quantify the amount of water evaporated.

\subsubsection{Mechanical properties}

The tensile strength and modulus of crosslinked electrospun gelatin samples were determined both in the dry and wet state using a texturometer (TA.XT Plus model, Stable Micro System SMD, England) with a $5 \mathrm{~N}$ load cell. Mechanical tests were carried out in a 
controlled environment at RT and relative air humidity of $45 \%$. The gauge length was 15 $\mathrm{mm}$ and the test speed was $1 \mathrm{~mm} \cdot \mathrm{s}^{-1}$. At least five individual samples were tested from each group and measurements were reported as mean \pm standard deviation according the statistical method used (mixed effect model).

\subsection{In vitro studies}

Human dermal neonatal fibroblasts (hDNF) isolated from the foreskin of healthy male newborns (ZenBio) were cultured, expanded, and maintained in Dulbecco's modified eagle medium (DMEM) (Gibco), at $37^{\circ} \mathrm{C}$ in a humidified atmosphere of $5 \% \mathrm{CO}_{2}$. The

culture medium was changed twice a week and cells were trypsinized $(0.25 \%$ trypsin/0.05\% ethylenediamine tetraacetic acid (EDTA)/0.1\% glucose in PBS (pH 7.5)) when they reached $70-80 \%$ of confluence. Cells from passages between 8 and 11 were used in this study.

\subsubsection{Cytotoxicity}

To assess cytotoxicity, electrospun meshes were tested in direct (samples) and indirect (leachables) contact under different pre-conditions (washed and non-washed in ultrapure water). Samples were sterilized with UV light followed by washing during $24 \mathrm{~h}$. hDNF cells were seeded in culture wells for $24 \mathrm{~h}$ at a density of $2 \times 10^{4}$ cells/well. $24 \mathrm{~h}$ later, samples (direct contact) and culture medium having been in contact with samples (indirect contact) were incubated with the cells for another $24 \mathrm{~h}$. The culture medium was then removed from the wells and fresh basal medium with $20 \% \mathrm{v} / \mathrm{v}$ resazurin (Sigma) was added. Cells were incubated $\left(37^{\circ} \mathrm{C}, 5 \% \mathrm{v} / \mathrm{v} \mathrm{CO}_{2}\right)$ for an additional $2 \mathrm{~h}$ period, after which $300 \mu \mathrm{L}$ per well were transferred to a black 96-well plate and measured (Ex at $530 \mathrm{~nm}$, Em at $590 \mathrm{~nm}$ ) using a micro-plate reader (Synergy MX, BioTek). The control consisted in cells alone.

For the quantification of the total double-stranded DNA (dsDNA) content, the cell pellets were recovered from wells and washed with phosphate buffered saline (PBS). The suspension was then centrifuged (10 $000 \mathrm{rpm}, 5 \mathrm{~min})$ and then stored at $-20^{\circ} \mathrm{C}$ until 
further analysis. The dsDNA quantification was performed using the Quant-iT PicoGreen dsDNA kit (Molecular Probes, Invitrogen), according to the manufacturer's protocol. Briefly, the samples were thawed and lysed in 1\% v/v Triton X-100 (in PBS) for 1 h at 250 rpm at $4^{\circ} \mathrm{C}$. Then, they were transferred to a black 96 -well plate with clear bottom (Greiner) and diluted in Tris-EDTA buffer (200 mM Tris-HCl, 20 mM EDTA, pH 7.5). After adding the Quant-iT PicoGreen dsDNA reagent, samples were incubated for 5 min at RT in the dark, and fluorescence was measured using a microplate reader (Ex at 480, Em at $520 \mathrm{~nm})$.

\subsubsection{Cell metabolic activity and proliferation}

Cell metabolic activity and proliferation assays were performed using hDNF cells seeded on electrospun meshes at a cell density of $1 \times 10^{4}$ cells per sample. To promote an efficient cell penetration into the mesh the seeding was performed with only $10 \mu \mathrm{L}$. After $2 \mathrm{~h}$ medium up to $500 \mu \mathrm{L}$ was added and cultured during 7 days. Metabolic activity was estimated using the resazurin-based assay, using electrospun meshes without cells as control. For the proliferation assay samples were tested in direct contact with hDNF cells and pre-washed with ultrapure water. Afterwards, they were cultured for 7 days, and their metabolic activity was measured at days 1,3 and 7 .

\subsubsection{Cell morphology and fibronectin deposition}

For the same time-points as for the cell metabolic activity (1, 3 and 7 days), cells seeded in electrospun meshes were stained for filamentous actin (F-actin), nuclei (Dapi) and fibronectin (FN) deposition. Briefly, samples were washed with PBS, fixed for 20 min in 4 wt- $\%$ paraformaldehyde (PFA, Sigma), and permeabilized with $0.2 \%$ Triton X-100 (Sigma) for $7 \mathrm{~min}$. Samples were then incubated for $1 \mathrm{~h}$ with $1 \mathrm{wt}-\%$ bovine serum albumin (BSA, Merck) in PBS. For FN staining, electrospun meshes were incubated overnight at $4^{\circ} \mathrm{C}$ with rabbit anti-fibronectin ( $\mathrm{f3648}$, Sigma, 1: 300 ) and then with the goat anti-rabbit secondary antibody Alexa Fluor ${ }^{\circledR} 488 \mathrm{~F}\left(\mathrm{ab}^{\prime}\right)_{2}$ fragment (Molecular Probes-Invitrogen, 1:2000, $2 \mathrm{~h}$ at RT). Subsequently, samples were incubated with the conjugated probe 
phalloidin/Alexa Fluor® 594 (Molecular Probes-Invitrogen, 1:40, 1h at RT) for F-actin staining. Samples were then washed three times with the PBS solution and nuclei were counterstained with 40,6-diamidino-2-phenylindole dihydrochloride (DAPI, Sigma, 0.1 $\mathrm{mg} \cdot \mathrm{mL}^{-1}$ ) in vectashield (vector), just before confocal visualization (CLSM, Leica SP2AOBS, Leica Microsystems) using LCS software (Leica Microsystems). The scanned Z-series were projected onto a single plane and pseudo-colored using ImageJ. The cells cultured in electrospun meshes were also visualized trough SEM to evaluate their morphology. Briefly, samples were washed with PBS, fixed for 30 min in 2.5 wt- $\%$ glutaraldehyde (GA, Fluka), and dehydrated with a successive graded ethanol series $(40,50,70,90$ and $100 \%)$ for 15 min each. After that, critical point drying (CPD7501, Polaron Range) was performed to ensure the complete dehydration of samples.

\subsection{Statistical analyses}

All data points were expressed as mean \pm standard deviation (SD). Statistical analysis (Levene's and T test) was carried out using IBM SPSS Statistics 20.0 with $99 \%$ confidence level for extent of crosslinking and cytotoxicity assays. Linear mixed model (LMM) was used to test differences between the effects of concentration, time and environment (wet and dry) in Young's Modulus, tensile strength at break and elongation at break. Concentration, time and environment were treated as a fixed factor and replication experiment was treated as a random factor to take into account possible heterogeneity of the samples in each set. Parameters estimation were performed by Ime package and multiple comparison adjustment were performed by mulcomp package from the R statistical software [31]. The results were considered statistically significant when $p \leq 0.05\left(^{*}\right)$.

\section{Results and discussion}

\subsection{Macroscopic and morphological characterization}

An optimal scaffold requires a highly porous (>60-90\%) and fully interconnected structure to provide a large surface area for cell ingrowth, uniform cell distribution, easy access to 
oxygen and nutrients by the cells, facilitating vascularisation [32-35]. The porosity of electrosopun meshes can be influenced by several parameters such as the fiber diameter and fibers density per area. The theoretical values calculated for the porosity of electrospun meshes produced (Table 1) range between 97.37 (2\% v/v BDDGE,72h) and $98.76 \%$ (4\% v/v BBDGE, 24h). The results showed that higher diameters yield slightly high mesh porosity values as a consequence of less fibers packing, leaving larger spaces between fibers. However, all sample demonstrated a high degree of porosity.

SEM morphological analyses of electrospun gelatin meshes with and without BDDGE are presented in Fig. 1. The results show that the obtained electrospun meshes present an uniform random deposition, with well-defined filaments and without beads. The in situ crosslinked fibers keep their morphology after incorporating BDDGE in the polymeric solution prior to fiber spinning. Fiber diameters strongly depend on both the amount of crosslinker and the incubation time (Table 1). For all samples, the fiber diameter generally decreased with increasing the crosslinking reaction time in BDDGE as a consequence of new bonds formation, bringing the molecular chains closer and thereby decreasing the fiber diameter. Using $2 \%$ of BDDGE the diameter decreased from $346 \pm$ $158 \mathrm{~nm}$ at $24 \mathrm{~h}$ to $284 \pm 120 \mathrm{~nm}$ at $72 \mathrm{~h}$ of incubation. With $4 \%$ of BDDGE the diameter decreased from $378 \pm 137 \mathrm{~nm}$ at $24 \mathrm{~h}$ to $339 \pm 91 \mathrm{~nm}$ at $72 \mathrm{~h}$ of incubation and with $6 \%$ of BDDGE there is a reduction from $341 \pm 134 \mathrm{~nm}$ at $24 \mathrm{~h}$ to $276 \pm 88 \mathrm{~nm}$ at $72 \mathrm{~h}$. At $48 \mathrm{~h}$ of crosslinking reaction a non-agreement with the general trend was observed, which can be correlated with the instability associated to an incomplete reaction. 


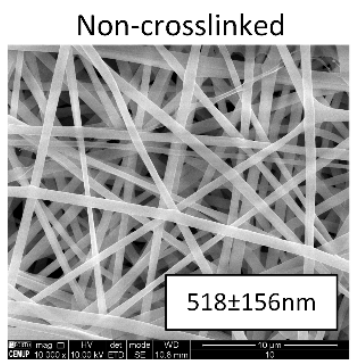

a)

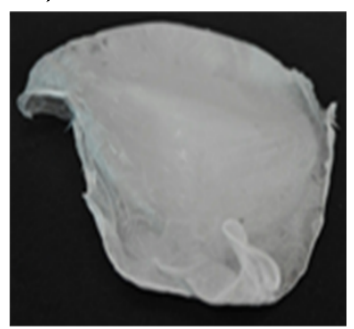

b)
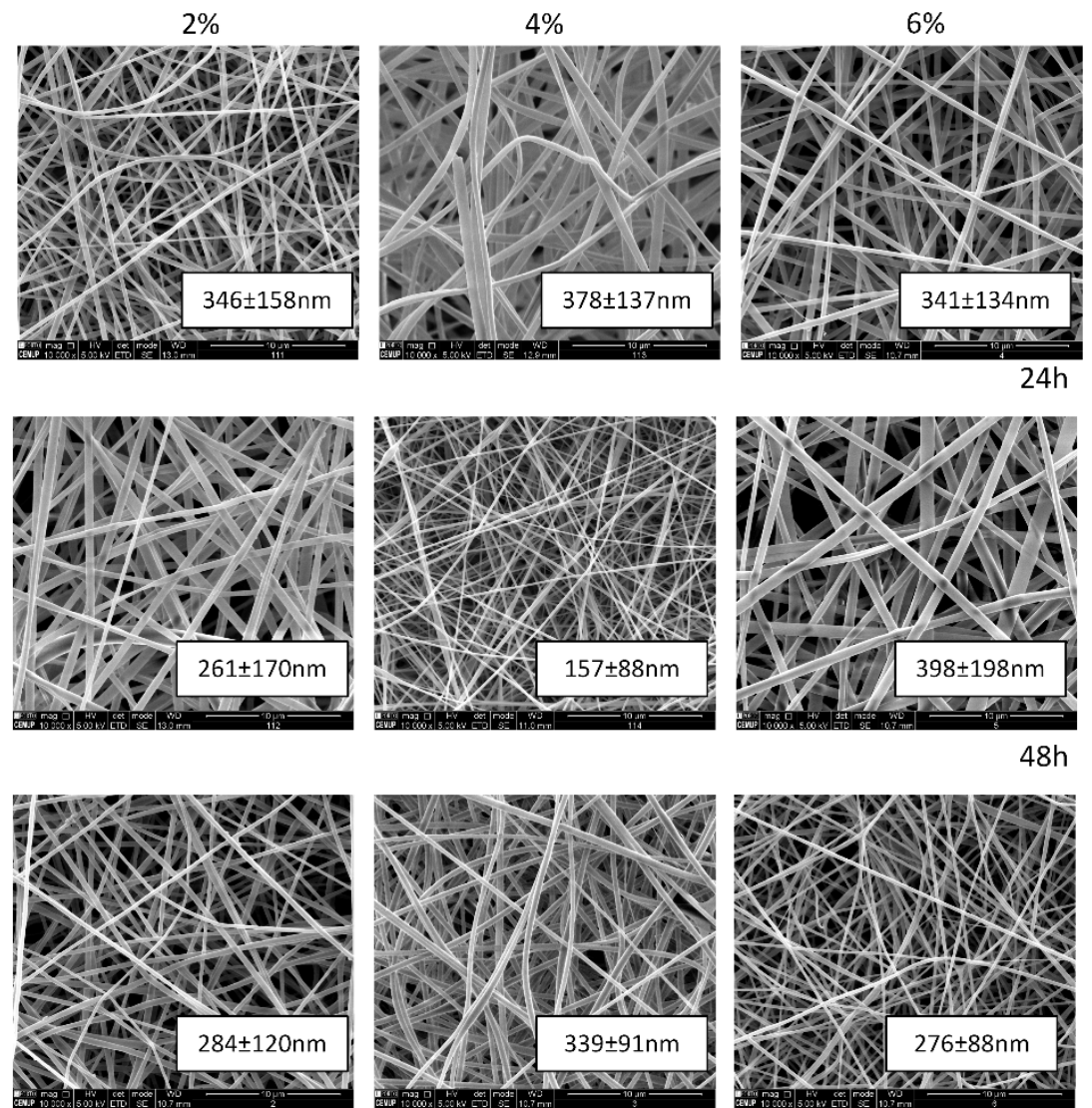

c)
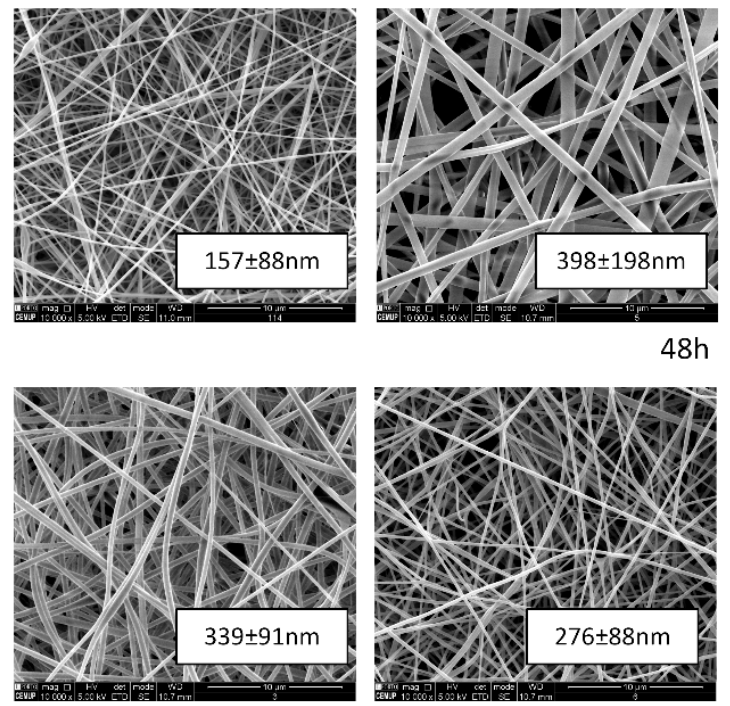

$48 \mathrm{~h}$

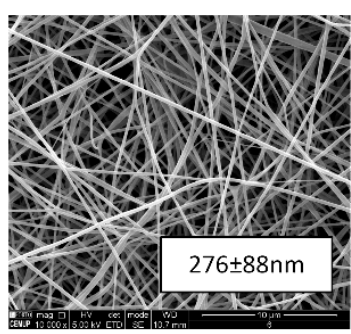

$72 \mathrm{~h}$

Figure 1. Morphological evaluation of gelatin electrospun meshes. a) Uncrosslinked sample, b) Electrospun mesh at macroscale. c) Electrospun gelatin nanofibrous meshes crosslinked with different concentrations of BDDGE at different time-points. Average fiber diameter is indicated in white background. Scale bars correspond to $10 \mu \mathrm{m}$. 
Table 1. Characterization of gelatin electrospun meshes produced. Mechanical properties correspond to tests performed on wet samples only. Statistical significance for $p<0.05$, (a) compared to $6 \%$ of BDDGE at the same incubation time, (b) compared to $4 \%$ of BDDGE at the same incubation time and (c) compared to $2 \%$ of BDDGE at the same incubation time.

\begin{tabular}{|c|c|c|c|c|c|c|c|c|c|c|c|}
\hline $\begin{array}{l}\text { BDDG } \\
E(\%)\end{array}$ & $\begin{array}{c}\text { Crosslinkin } \\
\text { g duration } \\
\text { (h) }\end{array}$ & $\begin{array}{l}\text { Crosslinking } \\
\text { degree }(\%)\end{array}$ & $\begin{array}{l}\text { Apparent } \\
\text { density }\end{array}$ & $\begin{array}{l}\text { Porosi } \\
\text { ty }(\%)\end{array}$ & $\begin{array}{l}\text { Average } \\
\text { fiber } \\
\text { diameter } \\
(\mathrm{nm})\end{array}$ & $\begin{array}{c}\text { Swelling degree } \\
(\%)\end{array}$ & $\begin{array}{c}\text { Dissolvability } \\
(\%)\end{array}$ & $\begin{array}{c}\text { Water vapor } \\
\text { permeability } \\
\left(\mathrm{g} / \mathrm{m}^{2} / \text { day }\right)\end{array}$ & $\begin{array}{c}\text { Elastic } \\
\text { modulus } \\
(\mathrm{MPa})\end{array}$ & $\begin{array}{c}\text { Tensile } \\
\text { strength } \\
\text { (MPa) }\end{array}$ & $\begin{array}{c}\text { Elongation at } \\
\text { break } \\
(\%)\end{array}$ \\
\hline \multirow{3}{*}{2} & 24 & $9.55 \pm 1.31^{\mathrm{a}}$ & 0.01222 & 98.30 & $\begin{array}{c}346 \pm \\
158\end{array}$ & $460.01 \pm 317.36$ & $\begin{array}{c}53.60 \pm \\
18.58\end{array}$ & $\begin{array}{c}2425.49 \pm \\
137.71\end{array}$ & $\begin{array}{l}0.77 \pm \\
0.45\end{array}$ & $0.26 \pm 0.15$ & $35.45 \pm 5.88$ \\
\hline & 48 & $\begin{array}{l}25.49 \pm \\
0.59^{\mathrm{a}, \mathrm{b}}\end{array}$ & 0.01250 & 98.26 & $\begin{array}{c}261 \pm \\
170\end{array}$ & $380.65 \pm 84.28$ & $15.27 \pm 6.23$ & $2359.52 \pm 91.13$ & $\begin{array}{l}0.42 \pm \\
0.23\end{array}$ & $0.05 \pm 0.02$ & $23.80 \pm 10.81$ \\
\hline & 72 & $\underset{\mathrm{a}, \mathrm{b}}{43.45 \pm 0.52}$ & 0.01893 & 97.37 & $\begin{array}{c}284 \pm \\
120\end{array}$ & $615.68 \pm$ & $\begin{array}{c}30.68 \pm \\
10.67\end{array}$ & $\begin{array}{c}2462.43 \pm \\
100.52\end{array}$ & $\begin{array}{c}0.31 \pm \\
0.11\end{array}$ & $0.08 \pm 0.06$ & $25.20 \pm 8.99$ \\
\hline \multirow[t]{2}{*}{4} & 48 & $\underset{b, c}{42.75 \pm 0.60}$ & 0.01471 & 97.96 & $157 \pm 88$ & $468.48 \pm 227.89$ & $23.91 \pm 5.33$ & $2647.62 \pm 54.22$ & $\begin{array}{c}0.60 \pm \\
0.26\end{array}$ & $0.12 \pm 0.10$ & $33.23 \pm 19.67$ \\
\hline & 72 & $65.94 \pm 0.23^{b}$ & 0.01579 & 97.81 & $339 \pm 91$ & $567.22 \pm 124.63$ & $\begin{array}{c}17.21 \pm \\
10.19 \\
\end{array}$ & $\begin{array}{c}2292.69 \pm \\
147.36\end{array}$ & $\begin{array}{l}0.30 \pm \\
0.15\end{array}$ & $0.04 \pm 0.03$ & $29.10 \pm 11.60$ \\
\hline \multirow{3}{*}{6} & 24 & $\begin{array}{c}59.53 \pm 0.97 \\
b, c\end{array}$ & 0.01339 & 98.14 & $\begin{array}{c}341 \pm \\
134\end{array}$ & $\begin{array}{c}2375.48 \pm \\
274.11\end{array}$ & $52.65 \pm 4.61$ & $\begin{array}{c}2111.36 \pm \\
115.50\end{array}$ & $\begin{array}{l}0.16 \pm \\
0.19\end{array}$ & $0.03 \pm 0.02$ & $15.04 \pm 8.32$ \\
\hline & 48 & $\underset{b, c}{67.57 \pm 2.04}$ & 0.01676 & 97.67 & $\begin{array}{c}398 \pm \\
198\end{array}$ & $\begin{array}{c}1291.11 \pm \\
142.93\end{array}$ & $38.06 \pm 4.72$ & $\begin{array}{c}2160.13 \pm \\
141.19\end{array}$ & $\begin{array}{l}0.33 \pm \\
0.15\end{array}$ & $0.04 \pm 0.02$ & $26.12 \pm 7.76$ \\
\hline & 72 & $72.81 \pm 1.70^{c}$ & 0.01798 & 97.50 & $276 \pm 88$ & $820.79 \pm 90.90$ & $28.43 \pm 7.99$ & $\begin{array}{c}2299.82 \pm \\
101.10\end{array}$ & $\begin{array}{c}0.43 \pm \\
0.24\end{array}$ & $0.02 \pm 0.01$ & $35.67 \pm 15.35$ \\
\hline
\end{tabular}


This seems to be confirmed by the fact that samples are more stable when incubated during $72 \mathrm{~h}$ with $4 \%$ or $6 \%$ of BDDGE, corresponding to $65.94 \%$ and $72.81 \%$ of crosslinking degree and a decrease of fiber diameter of $34.56 \%$ and $46.72 \%$, respectively, compared to the non-crosslinked gelatin mesh (518 $\pm 165 \mathrm{~nm}$ ) (Table 1 and Fig. 1a). Effectively, the decrease of standard deviation at the end of $72 \mathrm{~h}$ suggests the stabilization of the reaction.

\subsection{Physico-chemical and structural characterization}

Fourier transform infrared spectroscopy with attenuated total reflection (FTIR-ATR) analyses were performed to evaluate the interaction between gelatin and BDDGE on electrospun meshes using uncrosslinked gelatin as control. The different spectra obtained are shown in Fig. 2. The FTIR spectrum of gelatin (uncrosslinked) is characterized by strong and sharp peaks that include prominent absorption bands directly associated with the protein's secondary structure [36]. The FTIR spectra of crosslinked gelatin samples shows prominent peaks in four different amide regions, namely at $1700-1600 \mathrm{~cm}^{-1}$ corresponding to amide I, at $1565-1520 \mathrm{~cm}^{-1}$,corresponding to amide II, at $1240-670 \mathrm{~cm}^{-1}$ corresponding to amide III, and at $3500-3000 \mathrm{~cm}^{-1}$ corresponding to amide A [36-40]. The absorption of amide I contains contributions from the $\mathrm{C}=\mathrm{O}$ stretching vibration of amide group and a minor contribution from the $\mathrm{C}-\mathrm{N}$ stretching vibration [36]. Amide II absorption is related to $\mathrm{N}-\mathrm{H}$ bending and $\mathrm{C}-\mathrm{N}$ stretching vibrations. Amide III presents vibrations from $\mathrm{C}-\mathrm{N}$ stretching attached to $\mathrm{N}-\mathrm{H}$ in-bending with weak contributions from $\mathrm{C}-\mathrm{C}$ stretching and $\mathrm{C}=\mathrm{O}$ in-plane bending [41]. In samples crosslinked with BDDGE, at 2930 and $2890 \mathrm{~cm}^{-1}$, it is possible to observe intensity changes compared to the uncrosslinked gelatin spectrum, which are associated to the contribution of aliphatic moieties from BDDGE, confirming the incorporation of BDDGE into the gelatin matrix (Fig. 2 and Table 2) [39]. 


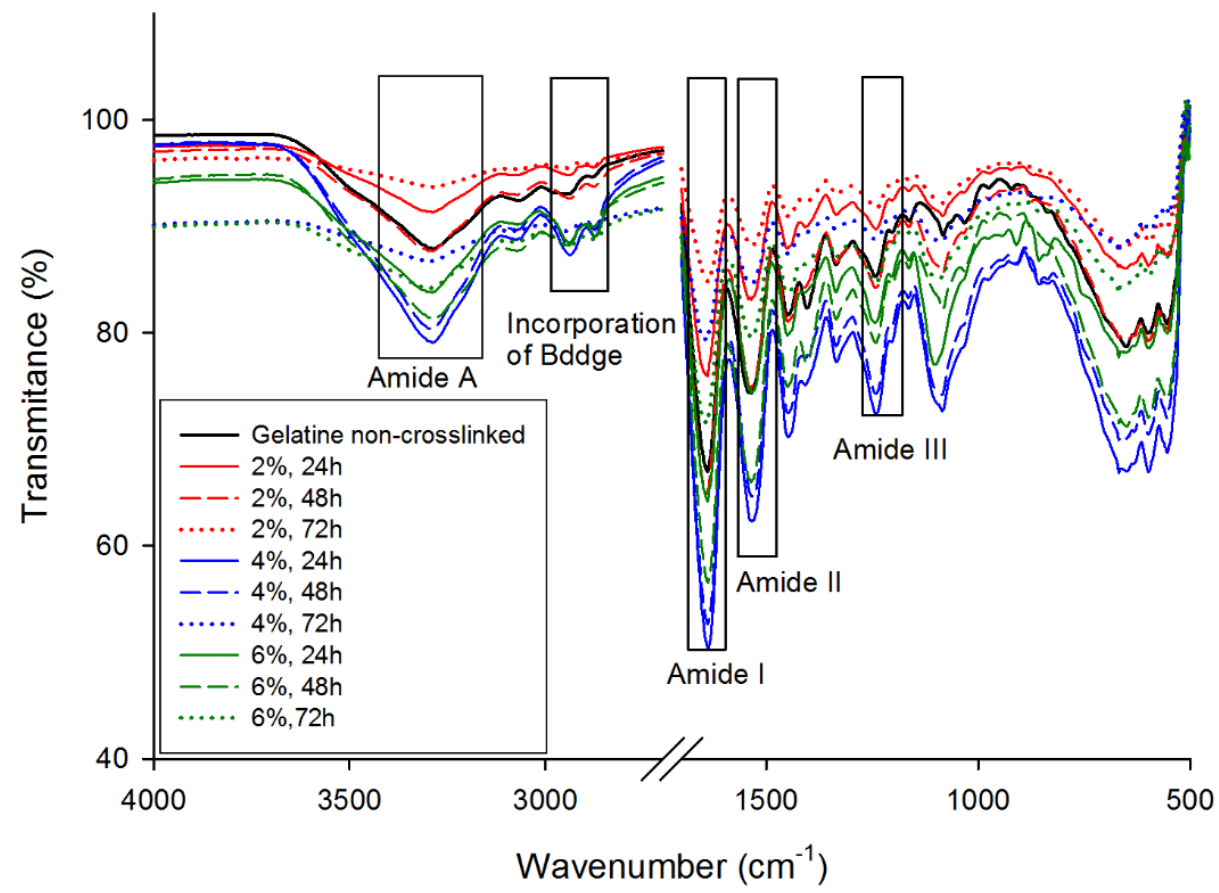

Figure 2. FTIR spectra of uncrosslinked and gelatin crosslinked with BDDGE at different crosslinking degrees.

Table 2. Ratio between non-crosslinked and crosslinked samples at 2930 and $2890 \mathrm{~cm}^{-1}$, ratio $\geq 1$ means presence of BDDGE.

\begin{tabular}{|c|c|c|c|}
\hline \multirow{3}{*}{$\begin{array}{c}\text { BDDGE } \\
(\%)\end{array}$} & $\begin{array}{c}\text { Crosslinking } \\
\text { duration (h) }\end{array}$ & \multicolumn{2}{|c|}{$\begin{array}{r}\text { Ratio between intensity of non-crosslinked and } \\
\text { crosslinked samples (a.u.) }\end{array}$} \\
\cline { 2 - 4 } & & $2930 \mathrm{~cm}^{-1}$ & $289 \mathrm{~cm}^{-1}$ \\
\hline \multirow{3}{*}{2} & 24 & 1.41 & 2.34 \\
\cline { 2 - 4 } & 48 & 0.99 & 2.47 \\
\cline { 2 - 4 } & 72 & 1.01 & 2.08 \\
\hline \multirow{3}{*}{4} & 24 & 1.02 & 2.23 \\
\cline { 2 - 4 } & 48 & 1.01 & 2.34 \\
\cline { 2 - 4 } & 72 & 1.01 & 1.70 \\
\hline \multirow{3}{*}{6} & 24 & 0.99 & 1.63 \\
\cline { 2 - 4 } & 48 & 0.98 & 2.49 \\
\cline { 2 - 4 } & 72 & 1.02 & 2.35 \\
\hline
\end{tabular}

The extension of crosslinking reaction was also assessed through UV/Vis used to quantify the crosslinking degree as a function of the amount of crosslinker and incubation time at different time-points. As expected, higher crosslinker amount and longer incubation times resulted in higher crosslinking degrees, showing that the crosslinking degree, and thus the properties of the obtained meshes can be easily tuned by simply 
varying the amount of crosslinker and the incubation time. For instance, using $2 \%$ of BDDGE incubated for $72 \mathrm{~h}$ resulted in a crosslinking degree of $43.45 \%$, although using $4 \%$ of BDDGE incubated for only $48 \mathrm{~h}$ resulted in a similar crosslinking degree $(42.75 \%)$. It is important to highlight that the maximum crosslinking degree reached was $72.81 \%$, corresponding to samples crosslinked in $6 \%$ of BDDGE and incubated for $72 \mathrm{~h}$. The reaction between BDDGE and gelatin occurs in acidic conditions due to the AA/TEA solution used to dissolve the gelatin, which results in protonation of the carboxylic acid groups (Fig. 3), and thereby limiting the achievement of $100 \%$ of crosslinking degree [39, 42, 43].<smiles>CCCCC(=O)OCC(O)COCCCCOCC(O)COC(=O)O</smiles>

Figure 3. Characteristic reaction between BDDGE and gelatin under acidic $\mathrm{pH}$.

\subsection{Water uptake, swelling, dissolvability and water vapor permeability}

The water uptake of biodegradable polymers is an important indicator of their hydrophilic/hydrophobic character and, therefore, their susceptibility to degrade by hydrolysis [44]. The water uptake makes the materials more flexible and promotes changes in the dimensions of the implant material [45]. Table 1 shows the correlation between the water uptake and the crosslinker concentration and incubation time. The uncrosslinked samples were not evaluated due to their high dissolvability in aqueous medium. The capability to absorb water is known to decrease with the increase of crosslinking degree as the polymer chains become closer due the new bond formation, making the mesh more dense, with higher retraction forces [39, 46]. This trend was also observed in this work, using gelatin crosslinked with BDDGE (4 and 6\% v/v) for different reaction times.

Concerning the swelling degree, a less predictable behavior was observed, especially using $2 \% \mathrm{v} / \mathrm{v}$ of BDDGE, where an instability associated to incomplete reaction was observed. The results obtained for $4 \%$ and $6 \%$ of BDDGE clearly show that the swelling 
degree is influenced by the hydrophilic character of BDDGE, significantly increasing (for $6 \%$, comparing to 2 and $4 \%$ ) with the increase of crosslinker content. This is probably due to an increase in $\mathrm{pH}$, leaving less protons available, increasing anion-anion repulsive forces and allowing the absorption of an increasing water volume [47, 48].

The dissolvability assay represents the amount of uncrosslinked material immediately dissolved by the medium. Similarly, to the swelling degree the dissolvability decreased with the increase of crosslinking degree due the presence of less unreacted components. Samples with the lowest crosslinking degree $(9.55 \pm 1.30 \%)$, corresponding to $2 \%$ of BDDGE at $24 \mathrm{~h}$, present $53.60 \pm 18.58 \%$ of dissolved matter. Samples with the highest crosslinking degree $(72.81 \pm 1.70 \%)$ present only $28.43 \pm 7.99 \%$ of dissolved material. Results show a clear evolution of swelling degree with the dissolution of samples with $4 \%$ and $6 \%$ of BDDGE.

An ideal wound dressing should control the water loss evaporation at an optimal rate. It should be permeable to maintain a moist environment avoiding wound dehydration. Therefore, the water vapor permeability (WVP) is one of the most important characteristics of wound dressings [49]. A wound with a dry environment causes tissue desiccation and consequently the tissue matrix becomes dehydrated, the cells die and a hard scab is formed [50]. Subsequently the keratinocytes have to pass beneath this scab to reach viable tissue, which consumes energy and time, and delays the wound healing process [49]. However, it is important to underline that a moist wound environment is not a wet wound environment, since excess of exudates will lead the patient to hypergranulation tissue formation in the wound bed and macerated periwound skin [49, 50]. Therefore, an important objective in providing topical wound care relies in selecting a dressing which can maintain a moist wound surface and, at same time, remove exudates [49-51]. The common permeation rate for healthy skin is $204 \mathrm{~g} / \mathrm{m}^{2} /$ day, while for injured skin can range from $279 \mathrm{~g} / \mathrm{m}^{2} /$ day, for a first-degree burn, to $5138 \mathrm{~g} / \mathrm{m}^{2} /$ day, for a granulating wound [52, 53]. For an ideal wound dressing a rate of $2500 \mathrm{~g} / \mathrm{m}^{2} /$ day is recommended to provide an adequate level of moisture without risking wound 
dehydration $[49,52,54]$. The water vapor permeability through the gelatin electrospun meshes ranges between $2111.36 \pm 115.5$ and $2647.62 \pm 54.22 \mathrm{~g} / \mathrm{m}^{2} /$ day, which is in the range of recommended values. The WVP of dressings is influenced by the pore size and interconnectivity between pores, with meshes with small pores and packed fibers resulting in low permeability to water vapor [55]. From Table 1 it is possible to observe that there's a general tendency for a decrease in WVP values with the increase in crosslinking degree from 2 to $6 \%$ of BDDGE, which can be correlated with both the reduction in the fiber diameter and the increase in packing of the fibers.

\subsection{Mechanical characterization}

The mechanical properties of crosslinked electrospun gelatin meshes were also investigated as a function of amount of crosslinker and incubation time. Representative stress-strain curves for samples tested in the dry and wet state are shown in the Fig. $4 a$. From those curves, it was possible to obtain the Young's modulus, the tensile strength and the elongation at break. As expected, in the dry state gelatin electrospun meshes show the distinctive behaviour of brittle and rigid materials, having high values of Young's modulus and low values of elongation at break, as a consequence of a rigid protein network [39]. In the dry state, the Young's modulus of all samples (Fig. 4b) decrease by increasing the incubation time in BDDGE from 24 to $72 \mathrm{~h}$. The same trend was observed for samples in the wet state (Fig. 4b), except for samples crosslinked with $6 \%$ of BDDGE, which showed a slight increment from 24 to $72 \mathrm{~h}$ although not statistically significant. This decrease of the Young's modulus is related to the new bonds formed between polymer chains upon crosslinking, which increases the elasticity of the structure. It is worthwhile mentioning that samples in the wet state exhibited Young's modulus values between $0.16 \pm 0.19$ and $0.77 \pm 0.45 \mathrm{MPa}$, in comparison to $25.61 \pm 9.71$ to $113.09 \pm 63.85 \mathrm{MPa}$ in the dry state, clearly demonstrating that an hydrogel was formed after crosslinking with BDDGE, directly improving the elasticity of the produced meshes. Samples in the dry state present low elongation at break values due their rigid nature without water (Fig. 
4c). According to independent works of van Wachem and Zeeman, crosslinking of collagen with BDDGE at acidic $\mathrm{pH}$ promoted higher tensile strength and elongation at break values than the crosslinking reaction under alkaline conditions $[56,57]$. In the wet state, the elongation at break, up to $4 \%$ of crosslinker, decreased with the incubation time, while an increase was observed when $6 \%$ of BDDGE was used, as a consequence of the higher crosslinking degree achieved, leading to a denser and more compact structure. However for incomplete reactions (24h and $48 \mathrm{~h})$, at lower concentrations ( $2 \%$ and $4 \% \mathrm{v} / \mathrm{v}$ of BDDGE), the elongation and tensile strength was higher due to the plasticizing provided by the secondary hydroxyl groups and hydroxyl-terminated pendant groups from hydrolyzed un-reacted epoxides of BDDGE [39].

The tensile strength at break (TSB) is characterized by the maximum tensile stress supported before sample break. In both states (dry and wet) the TBS values decreased with the incubation time for each set and from the lower crosslinker concentration to the higher concentration. These variations can be attributed to the hydroxyl compounds from hydrolyzed un-reacted epoxides of BDDGE that may be attached to gelatin and can take part in weakening the interactions between protein chains, consequently enhancing the mobility of the macromolecules, reducing the Young's modulus and tensile strength and enhancing the elongation of electrospun meshes crosslinked with BDDGE [39].

For the human skin values of 2.9-150 MPa for Young's Modulus, 1-32 MPa for Tensile Strength and $17-207 \%$ for elongation at break can be considered as reference [58-61]. Several works have been demonstrating the similarity between the mechanical properties of skin tissue and electrospun meshes made by different materials and production strategies [62-64]. In terms of mechanical properties, the gelatin electrospun meshes developed here exhibit values generally lower than natural skin, although this behavior can be easily improved by developing hybrid structures to mimic the mechanical properties of the skin. 

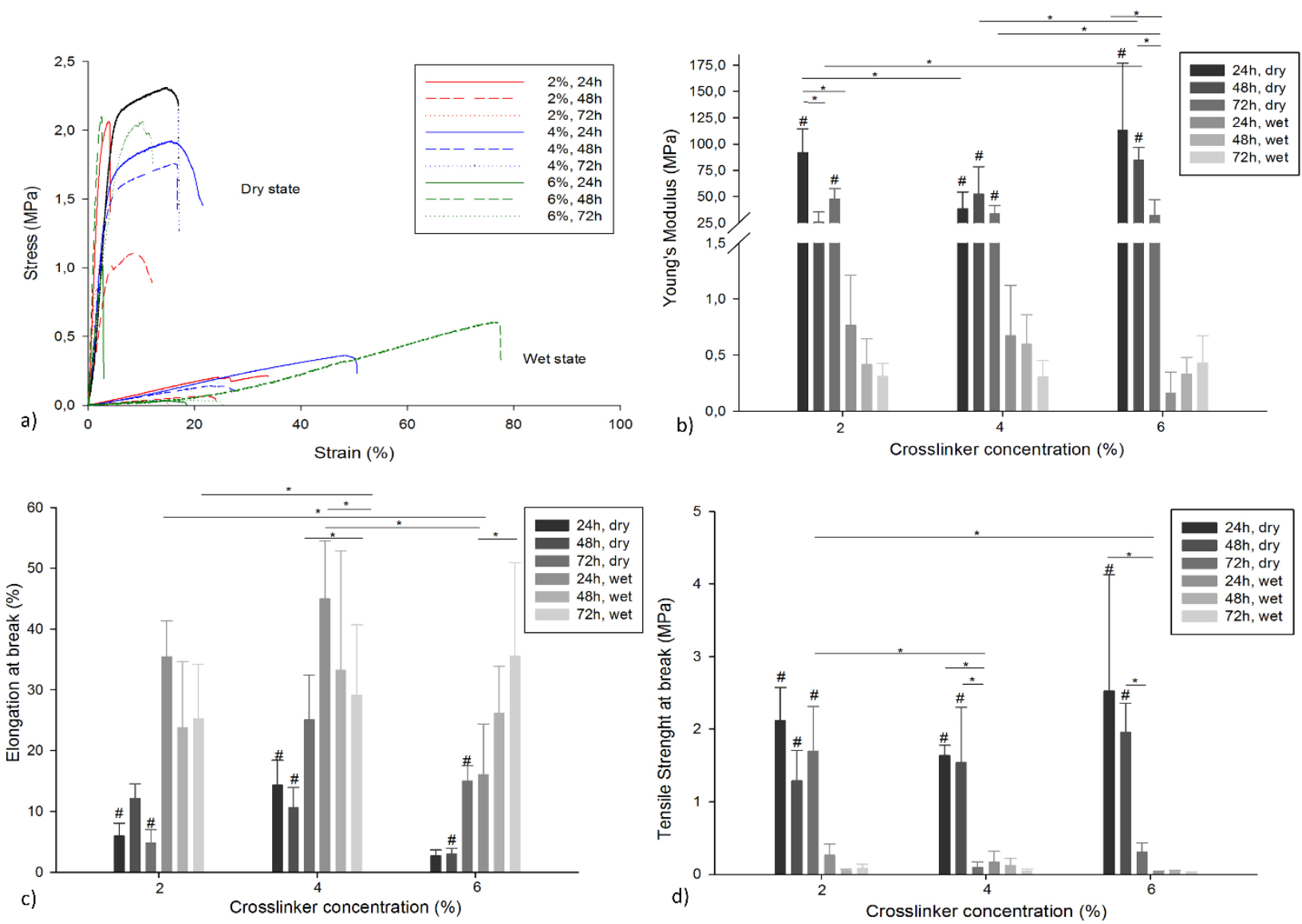

Figure 4. Mechanical behaviour of electrospun gelatin meshes in the wet and dry state. a) Stress-strain representative curves. b) Young's Modulus. c) Elongation at break. d) Tensile strength at break. Statistical significance for $p \leq 0.05\left(^{*}\right)$ and statistical significance for $p \leq 0.05$ compared to the same condition in wet state (\#).

\subsection{Biological behavior}

The cytotoxicity of the electrospun meshes was assessed using samples crosslinked in BDDGE at different concentrations (2, 4 and $6 \%$ ) during only $48 \mathrm{~h}$ which, according to the previous results, are representative of low, medium and high crosslinking degrees (35.18\%, $42.75 \%$ and $65.94 \%$, respectively).

The results presented in Fig. 5 show that fibroblasts remained metabolically active in all considered cases. After $24 \mathrm{~h}$ no cytotoxicity was observed even for samples with high amount of crosslinker and the additional washing step did not influence the toxicity, either in direct or indirect contact assays. In direct contact assays differences between samples with 2 and $6 \%$ of BDDGE exhibited statistical significance to the control (pre-washed or not). In indirect contact assays statistically significant differences were observed 
between samples with $2 \%$ BDDGE (control and washed) and between samples with $6 \%$ BDDGE (control and non-washed samples). In indirect contact assays results show an increased metabolic activity of cells in indirect contact with samples compared to the control, which can eventually be explained by the release of uncrosslinked gelatin to the medium. Gelatin displays many integrin-binding sites for cell adhesion, migration, proliferation, and differentiation due to the abundant Arg-Gly-Asp (RGD) amino acid sequences in its protein chain, which may enhance the metabolic activity of cells [65].

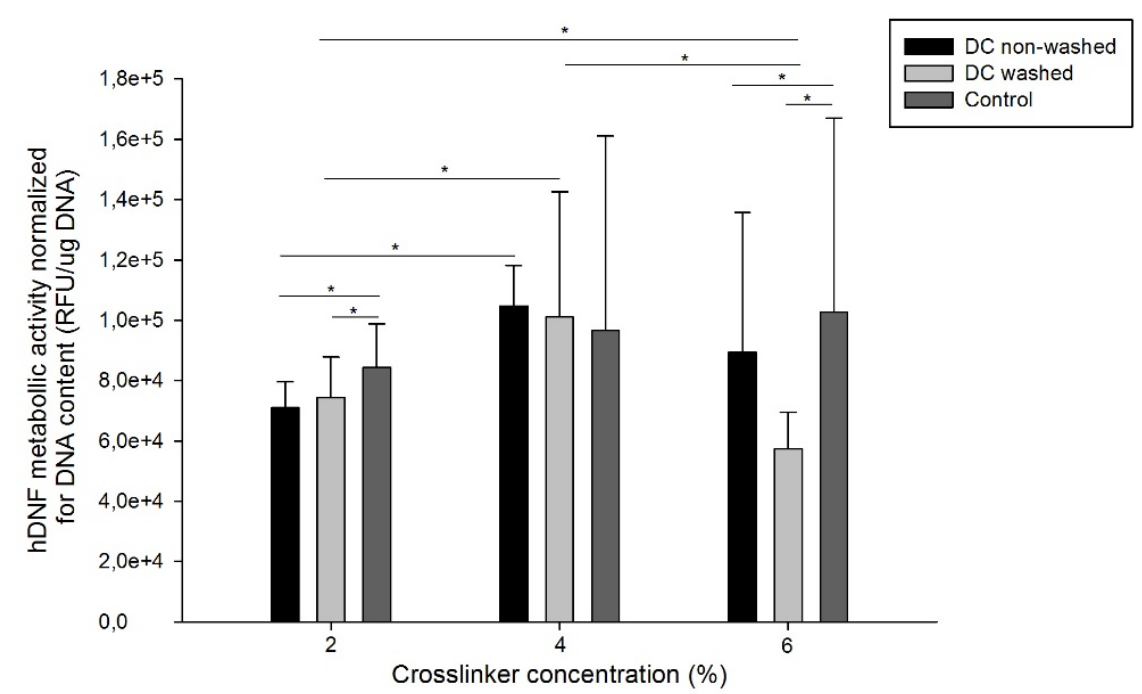

a)

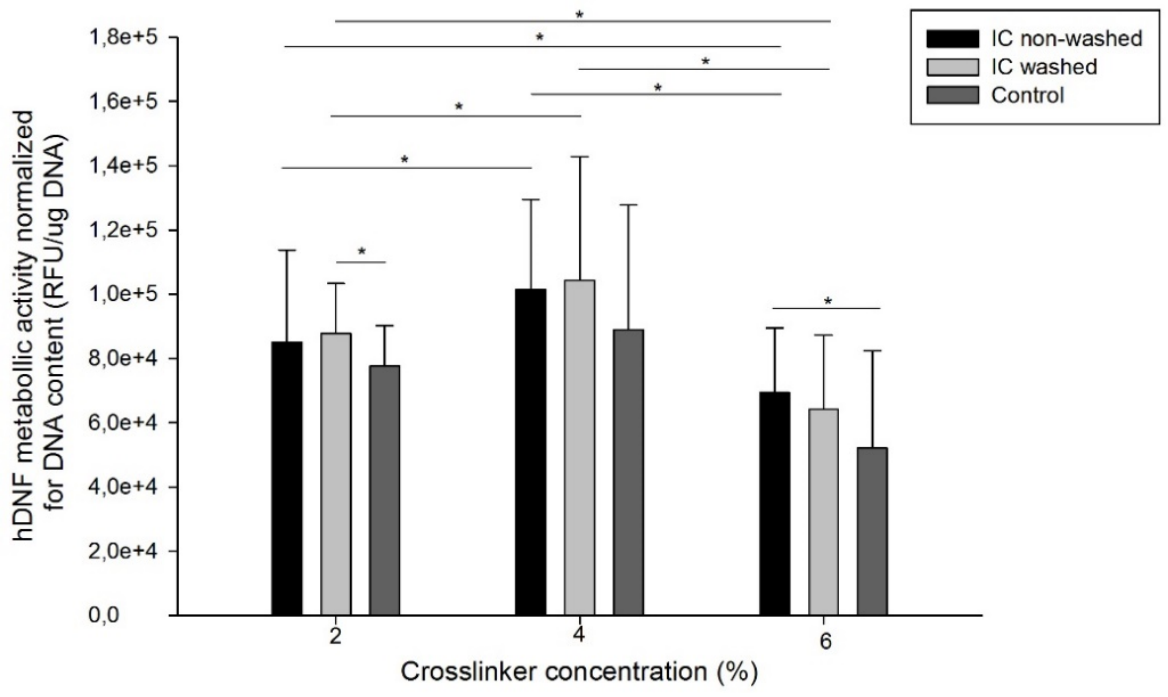

b)

Figure 5. Cytotoxicity assessment of electrospun gelatin meshes crosslinked with 2, 4 and $6 \%$ of BDDGE for $48 \mathrm{~h}$. a) Direct contact (DC) and b) Indirect contact (IC) with hDNF cells, using as cells alone as control. Statistical significance for $p \leq 0.05\left(^{*}\right)$. 
The proliferation of fibroblasts seeded on the electrospun gelatin meshes crosslinked with $4 \%$ of BDDGE ( $72 \mathrm{~h})$ during 7 days was accessed using the metabolic activity assay and cell morphology was further observed by SEM and confocal microscopy. Samples with $4 \%$ BDDGE (72h crosslinking) were selected according to the previous results. Since no samples showed cytotoxic effects the selection was based on the combination of adequate crosslinking degree, stability and mechanical properties but providing the lower amount of crosslinker. As shown in Fig. 6a fibroblasts cultured on the crosslinked gelatin electrospun meshes proliferated throughout the 7 days of culture. SEM images (Fig. 6b) show the intimate interaction between the cells and the nanofibrous structures. From day 1 to day 7 , in agreement with metabolic activity assessment, it is possible to observe an increase in cell number, as well as the integration and spreading of cells in the filamentous electrospun mesh. According to Jin and co-authors (2014) the integrinbinding sites available on gelatin promote cell adhesion and proliferation, and the nanosized fibers encourage better cell proliferation and signaling [65].

Electrospinning presents a unique ability to fabricate nanofiber-based scaffolds that best mimic the nanometer scale of the native ECM of skin [66]. Consequently, electrospun skin substitutes have been claimed to have increased potential to promote better cellular attachment, growth and differentiation due the high surface area, high aspect ratio and high microporosity provided by the low fiber diameter structure [67-69], which seems to be confirmed in the present work. Confocal microscopy images (Fig. 6b) of cells cultured on the electrospun meshes show the capability of fibroblasts to adhere and proliferate across the 7 days of culture and that they exhibit a proper phenotype, with a typical fibroblastic morphology. Additionally, after 7 days of culture, the production of fibronectin by the fibroblasts is clearly observed, sowing their ability to synthesize new ECM. Fibronectin is a large glycoprotein which plays an essential role in development, wound healing and angiogenesis [70]. 

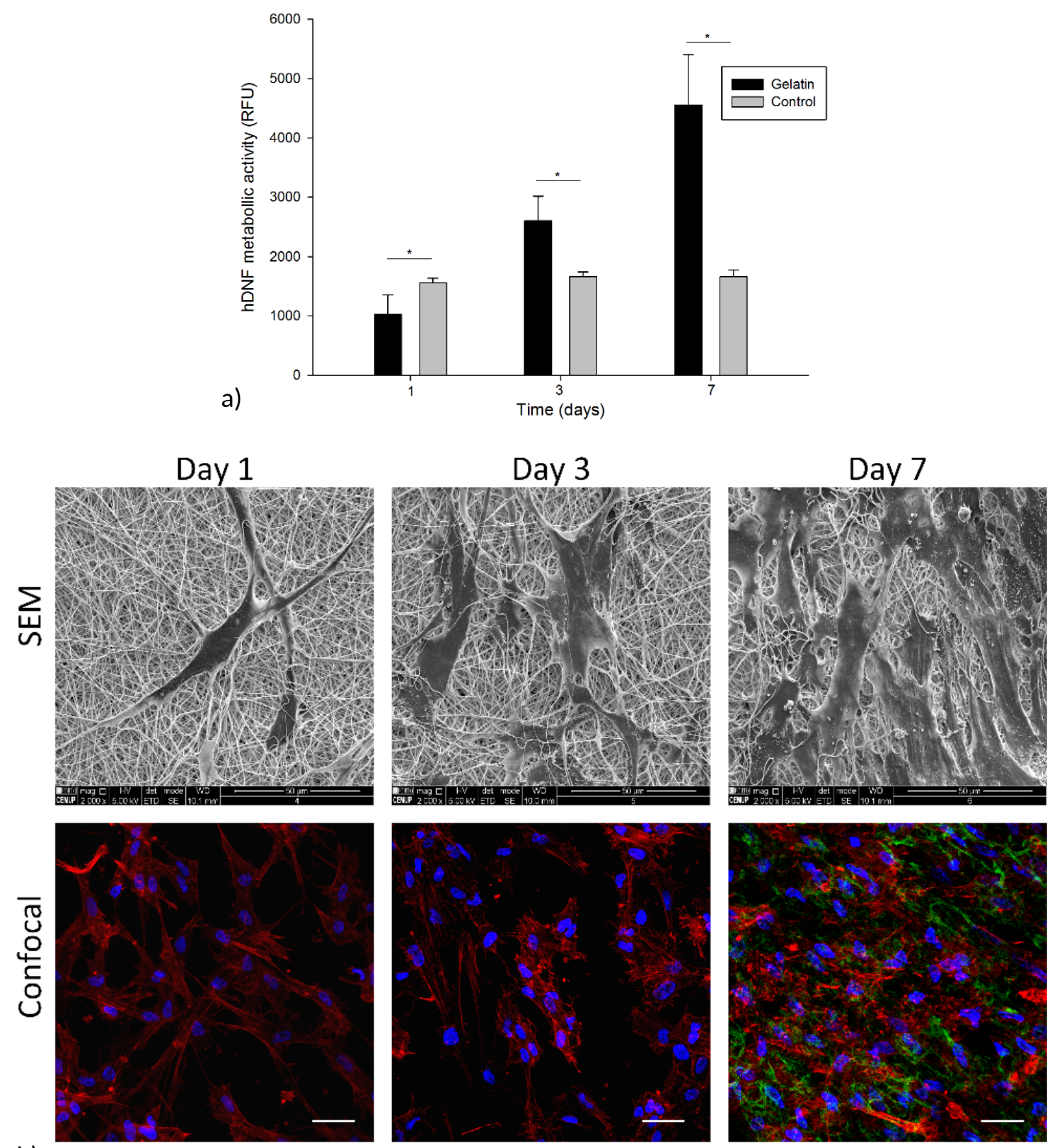

b)

Figure 6. Proliferation of hDNF cells on electrospun gelatin meshes. a) Metabolic activity, using electrospun meshes without cells as control. Statistical significance for $p \leq 0.05\left({ }^{*}\right)$. Scale bars correspond to $50 \mu \mathrm{m}$; b) SEM and confocal microscopy images of cells cultured on electrospun meshes (blue: nuclei; red: actin; green: fibronectin). Scale bars correspond to $50 \mu \mathrm{m}$.

Gelatin is a cost-effective, biocompatible, biodegradable and cell-interactive material, known for not causing any adverse immune response [65]. However, its fast degradation in aqueous media, associated to usually low mechanical properties, considerably limit its application [71]. Hence, new non-toxic gelatin crosslinkers are fundamental to improve 
the potential application of this biomaterial for tissue engineering applications. BDDGE is a widely used crosslinker in hyaluronic fillers already available in the market for several years. FDA determined that the use of unreacted BDDGE below 2 parts per million is safe since those trace amounts are prone to hydrolysis ultimately yielding $\mathrm{CO}_{2}$ and water [26]. Martucci and colleagues (2015) described for the first time the use of BDDGE as crosslinker of gelatin for preparing biodegradable films for food packaging. According to this study, the films produced by casting with different percentages of BDDGE $(0.5,1$ and $3 \%$ ), revealed a great potential for food packing due to their non-toxicity and enhanced mechanical properties [39]. However, this paper reports for the first time the use of BDDGE as in situ crosslinker of electrospun gelatin nanofibers for biomedical applications. Due to its similarity with the native ECM, gelatin electrospun meshes have been previously investigated as dressings for wound healing and drug release, revealing promising properties [9]. However, most of the crosslinkers used are toxic and/or nonstable, inducing changes in the fiber morphology due to the crosslinking bath/vapor used after fibers production $[9,72]$. The in situ crosslinking method used here represents a more effective crosslinking strategy than the traditional vapor crosslinking due to the homogenous mixing between polymer and crosslinker at the syringe prior to fiber formation [73]. The current study further demonstrates the possibility of modulating fiber diameter by controlling the in situ crosslinking parameters. Furthermore, the obtained electrospun meshes kept their morphology after the crosslinking process. Ultimately, gelatin electrospun meshes crosslinked with BDDGE show great potential as wound dressings due to their ideal water vapor permeability rate, stability on aqueous medium, adequate swelling degree, non-toxicity and capability to promote fibroblasts attachment, proliferation and production of ECM proteins.

\section{Conclusions}

The main purpose of this research work was to explore, for the first time, the potential of crosslinking gelatin fibers with BDDGE, improving its stability in aqueous media and 
mechanical properties. BDDGE-crosslinked gelatin meshes were synthesized, characterized and tested regarding their toxicity and potential as wound dressing. Electrospun gelatin fibers crosslinked with BDDGE were successfully produced, allowing to obtain meshes with a well-defined morphology and random deposition. The crosslinking degree could be tuned changing the amount of crosslinker and the incubation time, which allowed the control of both fiber diameter and mechanical properties. $4 \%$ and $6 \%$ BDDGE (both incubated for $72 \mathrm{~h}$ ) provided gelatin fibers with high crosslinking degree and stable diameters of $339 \pm 91$ and $276 \pm 88 \mathrm{~nm}$, respectively, although $4 \%$ BDDGE resulted in the best combination of mechanical properties. Cytotoxicity assays revealed no toxicity and proliferation assays showed that fibroblasts were able to attach and proliferate, producing new extracellular matrix within the electrospun meshes. Overall, this study demonstrated the potential of BDDGE as an alternative gelatin crosslinker due its non-toxicity and capability to tailor gelatin's mechanical and physical properties.

\section{Acknowledgements}

This study was supported by the Projects PTDC/BBB-ECT/2145/2014 and UID/Multi/04044/2013, financed by European Fonds Européen de Développement Régional (FEDER) through the Portuguese national programs Programa Operacional Factores de Competitividade (COMPETE), Portugal2020 and Norte2020, and by Portuguese funds through Fundação para a Ciência e a Tecnologia (FCT). This work is also supported by the research grants SFRH/BD/91104/2012 awarded to Juliana Dias and SFRH/BPD/90047/2012 awarded to Aureliana Sousa by FCT, and by the Investigator FCT program IF/00411/2013, awarded to Ana L. Oliveira. The authors thanks to CEMUP, University of Porto for the SEM images and, to Victoria Leiro and Marco Araújo for their support in chemical reactions interpretation. 


\section{References}

[1] S. MacNeil, Progress and opportunities for tissue-engineering skin, Nature.445 (2007)874-80.

[2] G. Casey, The physiology of the skin, Nursing Standard. 16 (2002)47-51.

[3] S.S. Zhou,D. Li,Y.M. Zhou,J.M. Cao, The skin function: a factor of anti-metabolic syndrome, Diabetology \& Metab Syndrom.4 (2012)1-11.

[4] L. Yildirimer,N.T.K. Thanh,A.M. Seifalian, Skin regeneration scaffolds a multimodal bottom-up approach, Trends Biotechnol.30 (2012)638-48.

[5] V.J. Reddy,S. Radhakrishnan,R. Ravichandran,S. Mukherjee,R. Balamurugan,S. Sundarrajan,S. Ramakrishna, Nanofibrous structured biomimetic strategies for skin tissue regeneration, Wound Rep Reg. (2013)21116.

[6] P. Zahedi,I. Rezaeian,S.O. Ranaei-Sidat,S.H. Jafari,P. Supaphol, A review on wound dressings with an emphasis on electrospun nanofibrous polymeric bandages, Polym. Adv. Technol. 21 (2009)77-95.

[7] A. Vasconcelos,A.C. Gomes,A. Cavaco-Paulo, Novel silk fibroin/ elastin wound dressings, Acta Biomaterialia. 8 (2012)3049-60.

[8] R.F. Pereira,C.C. Barrias,P.L. Granja,P.J. Bártolo, Advanced biofabrication strategies for skin regeneration and repair, Nanomedicine.8 (2013)603-21.

[9] Y.Z. Zhang,J. Venugopal,Z.M. Huang,C.T. Lim,S. Ramakrishna, Crosslinking of the electrospun gelatin nanofibers, Polymer. 47 (2006)2911-2917.

[10] A.G. Ward,A. Courts, The science and technology of gelatin, London:Academic Press, Inc.,(1977).

[11] E.P. Broderick,D.M. O'Halloran,Y.A. Rochev,M. Griffin,R.J. Collighan,A.S. Pandit, Enzymatic stabilization of gelatin-based scaffolds, J Biomed Mater Res B Appl Biomater.72 (2005)37-42.

[12] C.W. Yung,L.Q. Wu,J.A. Tullman,G.F. Payne,W.E. Bentley,T.A. Barbari, Transglutaminase crosslinked gelatin as a tissue engineering scaffold, J Biomed Mater Res Part A. 83 (2007)1039-1046.

[13] K. Ulubayram,E. Aksu,S.I.D. Gurhan,K. Serbetci,N. Hasirci, Cytotoxicity evaluation of gelatin sponges prepared with different cross-linking agents, J. Biomater. Sci. Polym. (2002)1203-1219.

[14] J.P. Draye,B. Delaey,A. Van de Voorde,A. Van Den Bulcke,B. De Reu,E. Schacht, In vitro and in vivo biocompatibility of dextran dialdehyde cross-linked gelatin hydrogel films., Biomaterials. (1998)1677-1687.

[15] H.W. Sung ,D.M. Huang,W.H. Chang, R.N. Huang,J.C. Hsu, Evaluation of gelatin hydrogel crosslinked with various crosslinking agents as bioadhesives: In vitro study., J. Biomed. Mater. Res. (1999)520-530.

[16] R.R. Ray,S.C. Jana,G. Nanda, Immobilization of $\beta$-amylase from Bacillus megaterium B6 into gelatin film by cross-linking, J of applied bacterial. (1995)157162.

[17] S. Matsuda,H. Iwata,N. Se,Y. Ikada, Bioadhesion of gelatin films crosslinked with glutaraldehyde. , J Biomed Mater Res. (1999)20-7.

[18] S.M. Lien,W.T. Li,T.J. Huang, Genipin-crosslinked gelatin scaffolds for articular cartilage tissue engineering with a novel crosslinking method, Mater. Sci. Eng. Biomim. Mater. Sens. Syst. (2008)36-43.

[19] C.H. Yao,B.S. Liu,C.J. Chang,S.H. Hsu,Y.S. Chen, Preparation of networks of gelatin and genipin as degradable biomaterials, Mater Chem Phys. (2004)204-8.

[20] A.A. Apostolov,D. Boneva,E. Vassileva,J.E. Mark,S. Fakirov, Mechanical properties of native and crosslinked gelatins in a bending deformation., J. Appl. Polym. Sci. (2000)2041-8.

[21] Y. Ming-Kung,L. Yan-Ming,C. Kuang-Ming,D. Niann-Tzyy, L. Cheng-Che,Y. JennJong, A novel cell support membrane for skin tissue engineering: Gelatin film cross-linked with 2-chloro-1-methylpyridinium iodide., Polymer. (2011)996-1003;. 
[22] A. Bigi,G. Cojazzi,S. Panzavolta,K. Rubini,N. Roveri, Mechanical and thermal properties of gelatine films at different degrees of glutaraldehyde crosslinking, Biomaterials.(2001)763-768.

[23] J.F. Martucci,A. Accareddu,R.A. Ruseckaite, Preparation and characterization of plasticized gelatin films cross-linked with low concentrations of glutaraldehyde, J.. Materials Sci.(2012)2382-3292.

[24] J. Guo,L. Ge,X. Li,C. Mu,D. Li, Periodate oxidation of xanthan gum and its crosslinking effects on gelatin-based edible films, Food Hydrocolloids.(2014)243-250.

[25] D. Enea,F. Henson,S. Kew,J. Wardale,A. Getgood,R. Brooks,N. Rushton, Extruded collagen fibres for tissue engineering applications: effect of crosslinking method on mechanical and biological properties, Journal of Material Science: Materials in Medicine.(2011)1569-1578.

[26] K. De Boulle,R. Glogau,T. Kono,M. Nathan,A. Tezel,J.-X. Roca- Martinez,S. Paliwal,D. Stroumpoulis, A review of the metabolism of 1,4-butanediol diglycidyl ether-crosslinked hyaluronic acid dermal fillers, Dermatologic Surg. (2013)17581766.

[27] J. Zhang,X. Ma,D. Fan,C. Zhu,J. Deng,J. Hui,P. Ma, Synthesis and characterization of hyaluronic acid/human-like collagen hydrogels, Materials Science and Engineering: C.(2014)547-554.

[28] W. He,Z. Ma,T. Yong,W.E. Teo,S. Ramakrishna, Fabrication of collagen-coated biodegradable polymer nanofiber mesh and its potential for endothelial cells growth, Biomaterials. (2005)7606-761.

[29] M.-K. Yeh,Y.-M. Liang,K.-M. Cheng,N.-T. Dai,C.-C. Liu,J.-J. Young, A novel cell support membrane for skin tissue engineering: Gelatin film cross-linked with 2chloro-1-methylpyridinium iodide, Polymer. (2011)996-1003.

[30] I. ASTM, Standard test methods for water vapor transmission of materials, in E96/E96M-10.

[31] R.C. Team, R: A language and environment for statistical computing., ed. R.F.f.S. Computing. 2014, Vienna, Austria.

[32] F.J. O'Brien, Biomaterials \& scaffolds for tissue engineering, MaterialsToday. 14 (2011)88-95.

[33] C.A. Léon y Léon, New perspectives in mercury porosimetry, Advances in Colloid and Interface Science.76-77 ( 1998)341-372,.

[34] T. Garg,O. Singh,S. Arora,R.S.R. Murthy, Scaffold: A Novel Carrier for Cell and Drug Delivery, , Critical Reviews ${ }^{\mathrm{TM}}$ in Therapeutic Drug Carrier Systems.29 (2012)1-63.

[35] T.M. Freyman,I.V. Yannas,L.J. Gibson, Cellular materials as porous scaffolds for tissue engineering, Prog Mater Sci. .46 (2001)273-82.

[36] N. Cebi,M.Z. Durak,O.S. Toker,O. Sagdic,M. Arici, An evaluation of Fourier transforms infrared spectroscopy method for the classification and discrimination of bovine, porcine and fish gelatins, Food Chemistry. 190 (2016)1109-1115.

[37] M. Nagarajan,S. Benjakul,T. Prodpran,P. Songtipya,H. Kishimura, Characteristics and functional properties of gelatin from splendid squid (Loligoformosana) skin as affected by extraction temperatures, Food Hydrocolloids.29 (2012)389-397.

[38] D. Hashim,M.Y. Che,R. Norakasha,M. Shuhaimi,Y. Salmah,Z. Syahariza, Potential use of Fourier transform infrared spectroscopy for differentiation of bovine and porcine gelatins, Food Chemistry.118 (2010)856-860.

[39] J.F. Martucci,J.P. Espinosa,R.A. Ruseckaite, Physicochemical properties of films based on bovine gelatin cross-linked with 1,4-butanediol diglycidyl ether, Food Bioprocess Technol. (2015)1645-1656.

[40] R. Núñez-Flores,B. Giménez,F. Fernández-Martín,M.E. López-Caballero,M.P. Montero,M.C. Gómez-Guillén, Physical and functional characterization of active fish gelatin films incorporated with lignin, Food Hydrocolloids.39 (2013)243-250. 
[41] J. Bandekar, Amide modes and protein conformation, Biochimica et Biophysica Acta: Protein Structure and Molecular Enzymology.1120 (1992)123-143.

[42] L. Shecter,J. Wynstra,R.P. Kurkjy, Glycidyl ether reactions with amines, Ind. Eng. Chem. .48 (1956).

[43] R.G. Paul,A.J. Bailey, Chemical Stabilisation of Collagen as a Biomimetic, The Scientific World Journal.3 (2003)138-155.

[44] M.M. Hohmann,M. Shin,G. Rutledge,M.P. Brenner, Electrospinning and electrically forced jets I stability theory, Phys. Fluid. (2001)2201-2220.

[45] H.S. Azevedo,M.G. Francisco,R.L. Reis, In Vitro Assessment of the Enzymatic Degradation of Several Starch Based Biomaterials, Biomacromolecules.4 (2003)1703-1712.

[46] G. Vargas,J.L. Acevedo,J. López,J. Romero, Study of cross-linking of gelatin by ethylene glycol diglycidyl ether, Materials Letters. 62 (2008)3656-3658.

[47] N.V. Gupta,H.G. Shivakumar, Investigation of Swelling Behavior and Mechanical Properties of a pH-Sensitive Superporous Hydrogel Composite, Iranian Journal of Pharmaceutical Research.11 (2012)481-493.

[48] H.K. Ju,S.Y. Kim,Y.M. Lee, pH/temperature-responsive behaviors of semi-IPN and comb-type graft hydrogels composed of alginate and poly $(\mathrm{N}-$ isopropylacrylamide), Polymer.42 (2001)6851- 6857.

[49] S.-Y. Gu,Z.-M. Wang,J. Ren,S.-Y. Zhang, Electrospinning of gelatin and gelatin/poly(L-lactide) blend and its characteristics for wound dressing Materials Science and Engineering C. 29 (2009)1822-1828.

[50] C.K. Field,M.D. Kerstein, Overview of wound healing in a moist environment, The American Journal of Surgery.16 (1994)2-6.

[51] M. Abrigo,S.L. McArthur,P. Kingshott, Electrospun Nanofibers as Dressings for Chronic Wound Care: Advances, Challenges, and Future Prospects, Macromol. Biosci. .14 (2014)772-792.

[52] L.O. Lamke,G.E. Nilsson,H.L. Reithner, The evaporative water loss from burns and the water-vapour permeability of grafts and artificial membranes used in the treatment of burns, Burns.3 (1977)159-165.

[53] R. Dave,H.M. Joshi,V.P. Venugopalan, Biomedical evaluation of a novel nitrogen oxides releasing wound dressing, J Mater Sci: Mater Med.23 (2012)3097-3106.

[54] S. Gustaitea,J. Kazlauskea,J. Bobokalonova,S. Perni,V. Dutschkc,J. Liesienea,P. Prokopovich, Characterization of cellulose based sponges for wound dressings, Colloids and Surfaces A: Physicochem. Eng. Aspects. 480 (2015)336-342.

[55] P.I. Morgado,A.A. Ricardo,I.J. Correia, Asymmetric membranes as ideal wound dressings: An overview on production methods, structure, properties and performance relationship, Journal ofMembrane Science.490 (2015)139-151.

[56] P.B. van Wachem,R. Zeeman,P.J. Dijkstra,J. Feijen,M. Hendriks,P.T. Cahalan,M.J.A. van Luyn, Characterization and biocompatibility of epoxycrosslinked dermal sheep collagens, J. Biomed.Mater. Res.47 (1999)270-277.

[57] R. Zeeman,P.J. Dijkstra,P.B. van Wachem,M.J.A. van Luyn,M. Hendriks,P.T. Cahalan,J. Feijen, Crosslinking and modification of dermal sheep collagen using 1,4-butanediol diglycidyl ether, J.Biomed. Mater. Res. .46 (1999)424-433.

[58] $\mathrm{H}$. Vogel, Age dependence of mechanical and biochemical properties of human skin, Bioengineering and the skin.3 (1987).

[59] L. Jansen,P. Rottier, Some mechanical properties of human abdominal skin measured on excised strips, Dermatologica.117 (1985)65-83.

[60] C. Jacquemoud,K. Bruyere-Garnier,M. Coret, Methodology to determine failure characteristics of planar soft tissues using a dynamic tensile test, Journal of Biomechanics. 40 (2007)468-475.

[61] J.-f. Pan,N.-H. Liu,H. Sun,F. Xu, Preparation and Characterization of Electrospun PLCL/Poloxamer Nanofibers and Dextran/Gelatin Hydrogels for Skin Tissue Engineering, PLoS ONE. 9 (2014) e112885. 
[62] M. Gümüşderelioğlu,S. Dalkıranoğlu,R.S.T. Aydın,S. Çakmak, A novel dermal substitute based on biofunctionalized electrospun PCL nanofibrous matrix, J Biomed Mater Res Part A. 98 (2011)461-472.

[63] D. Atila,D. Keskin,A. Tezcaner, Cellulose acetate based 3-dimensional electrospun scaffolds for skin tissue engineering applications, Carbohydrate Polymers. 133 (2015)251-261.

[64] E.J. Lee,J.H. Lee,L. Jin,O.S. Jin,Y.C. Shin,S.J. Oh,J. Lee,S.-H. Hyon,D.-W. Han, Hyaluronic Acid/Poly(lactic-co-glycolic acid) Core/Shell Fiber Meshes Loaded with pigallocatechin-3-O-Gallate as Skin Tissue Engineering Scaffolds, J. Nanosci. Nanotechnol.14 (2014)8458-63.

[65] G. Jin,Y. Li,M.P. Prabhakaran,W. Tian,S. Ramakrishna, In vitro and in vivo evaluation of the wound healing capability of electrospun gelatin/PLLCL nanofibers, Journal of Bioactive and Compatible Polymers.29 (2014)628-645.

[66] J.R. Dias,P.L. Granja,P.J. Bártolo, Advances in electrospun skin substitutes, Progress in Materials Science.84 (2016)314-334.

[67] W. Cui,Y. Zhou,J. Chang, Electrospun nanofibrous materials for tissue engineering and drug delivery, Sci. and technol. Adv. Mater.(2010)11014108.

[68] S. Pramanik,B. Pingguan-Murphy,N.A.A. Osman, Progress if key strategies in development of electrospun scaffolds: bone tissue, Sci. Technol. Adv. Mater.(2012)131-13.

[69] W. Liu,S. Thomopoulos,Y. Xia, Electrospun nanofibres for regenerative medicine, Adv. Healthcare Mater.1 (2012)10-25.

[70] A. Hielscher,K. Ellis,C. Qiu,J. Porterfield,S. Gerecht, Fibronectin Deposition Participates in Extracellular Matrix Assembly and Vascular Morphogenesis, PLoS ONE.11 (2016)e0147600.

[71] A. Kasuya,S. Sobajima,M. Kinoshita, In vivo degradation and new bone formation of calcium phosphate cement-gelatin powder composite related to macroporosity after in situ gelatin degradation, J Orthop Res. 30 (2012)103-1111.

[72] S.R. Gomes,G. Rodrigues,G.G. Martins,M.A. Roberto,M. Mafra,C.M.R. Henriques,J.C. Silva, In vitro and in vivo evaluation of electrospun nanofibers of PCL, chitosan and gelatin: A comparative study., Materials Science and Engineering C.46 348-358.

[73] A.P. Kishan,R.M. Nezarati,C.M. Radzicki,A.L. Renfro,J.L. Robinson,M.E. Whitely,E.M. Cosgriff-Hernandez, In situ crosslinking of electrospun gelatin for improved fiber morphology retention and tunable degradation, J. Mater. Chem. B. $3(2015) 7930$. 
Highlights

> In situ crosslinking of gelatin electrospun fibers with BDDGE was explored.

$>$ The fibers morphology was keep after in situ crosslinking methodology.

$>$ Is possible control the fiber diameter ranging crosslinker amount and reaction time.

The use of BDDGE is an alternative gelatin crosslinker due to its non-toxicity.

$>$ Controlling the reaction is possible tailor gelatin's properties. 